\title{
Biochemical assessment of nutritional status in Indian mustard
}

\author{
Nisha Kumari ${ }^{1 *}$, Ram Avtar ${ }^{2}$, Bunty Sharma ${ }^{1}$, Babita Rani ${ }^{1}$, Veena Jain ${ }^{1}$ and R.K. \\ Sheoran $^{2}$ \\ ${ }^{1}$ Department of Chemistry and Biochemistry, Chaudhary Charan Singh Haryana Agricultural University, Hisar- \\ 125004 (Haryana), INDIA \\ ${ }^{2}$ Oilseeds Section, Department of Genetics and Plant Breeding, Chaudhary Charan Singh Haryana Agricultural \\ University, Hisar-125004 (Haryana), INDIA \\ *Corresponding author. E-mail: nishaahlawat211@gmail.com \\ Received: October 28, 2016; Revised received: February 14, 2017; Accepted: May 10, 2017
}

\begin{abstract}
The present investigation was carried out to evaluate the nutritional potential of five different Indian mustard genotypes. Fatty acid composition was determined in the oil, whereas seed meal was analyzed for limiting amino acids (tryptophan and methionine), protein content, glucosinolate content and antioxidant potential (DPPH free radical scavenging activity, total antioxidant activity and iron chelating activity). The monounsaturated fatty acids (MUFA) were found to be maximum in RH 0749 (58.70 \%) followed by RH (OE) 0801 (48.91 \%), JM 6011 (47.03 \%), EC 597328 and EC 597340 (45.77\%). Polyunsaturated fatty acids (PUFA) were observed maximum in EC 597340 (47.45\%).Glucosinolate content ranged from 42.80 (EC 597328) to $79.79 \mu \mathrm{mole} / \mathrm{g}$ defatted seed meal (EC 597340). The methanolic seed meal extract exhibited a concentration dependent elimination of DPPH free radicals. All the five genotypes showed about $50 \%$ inhibition in $3.0 \mathrm{mg}$ of dry seed meal. The highest total antioxidant activity $(20.41 \mathrm{mg} / \mathrm{g})$ and metal ion chelating activity $(32.58 \%)$ was observed in $\mathrm{RH} 0749$. Protein content varied from 33.57 [RH (OE) 0801] to $38.01 \%$ (RH 0749). Maximum methionine and tryptophan content were recorded in $\mathrm{RH} 0749$ ( 0.99 and $1.01 \mathrm{~g} / 100 \mathrm{~g}$ protein, respectively). Thus, $\mathrm{RH} 0749$ was observed as a potent variety in terms of total antioxidant activity, metal ion chelating activity, protein content, methionine and tryptophan content.
\end{abstract}

Keywords: Antioxidant, Fatty acids, Glucosinolates, Methoinine, Protein

\section{INTRODUCTION}

Indian mustard [Brassica juncea (L.) Czern \& Coss.] is one of the premier oilseed crop of India. It is the second largest oilseeds crop in India after soybean. It accounts for nearly $30 \%$ of the total production and contributes about $27 \%$ to edible oil of the country (Sutariya et al., 2011). It is an important source of edible oil and meal as well. Nutritional properties of mustard oil are determined by the fatty acid profile which includes palmitic, stearic, oleic, linoleic, linolenic, eicosenoic and erucic acids. Both linoleic and linolenic acids are essential fatty acids; however, less than $3 \%$ linolenic acid is preferred for oil stability. A balanced ratio of these essential fatty acids in mustard oil makes it desirable for edible purposes (Singh et al., 2014). Linolenic acid is being essential but it also reduces the shelf life of the oil. It causes auto-oxiadtion resulting in off-flavour (Priyamedha et al., 2014). Edible oil with $>2 \%$ erucic acid is undesirable for human consumption because it causes myocardial infarction and increased blood cholesterol.

Mustard seed meal is mostly used as animal feed but can also be utilized for production of value-added products (Bala and Singh, 2012). Seed meal contains high amounts of anti-nutritional compounds known as glucosinolates, the hydrolysis products of which have been reported to be dangerous to animal health, particularly in non-ruminants as they reduce the feed palatability by affecting the iodine uptake by the thyroid gland (Bell, 1984). The recommended concentration of glucosinolates is $<30 \mu \mathrm{mole} / \mathrm{g}$ defatted seed meal. Seed meal of mustard is a rich source of protein (32-40 $\%$ ) also. Mustard protein has a high nutritive value compared to other vegetable products due to its high biological value. The seed meal of mustard also has flavonoids, tocopherols, ascorbic acid etc. which exhibit antioxidant properties. Antioxidant compounds may function as free radical scavengers, complex of pro-oxidant metals, reducing agent and quenchers of singlet oxygen formation (Andlauer and Furst, 1998). Food industries have used effective synthetic antioxidants, consumers of food, however, prefer natural antioxidants on the basis of the assumption that natural compounds are safe (Halliwell, 2010). Thus, Indian mustard seed meal is an important source of natural antioxidants in the food industry as well as in the livestock industry for animal feed. The present study was therefore, undertaken with an objective to determine the nutritional and fatty acid profile of five different 
Indian mustard genotypes.

\section{MATERIALS AND METHODS}

Freshly threshed seeds of five genotypes of Indian mustard [RH 0749, RH (OE) 0801, JM 6011, EC 597328 and EC 597340] were used for carrying out the present study. Finely powdered seeds were then defatted with n-hexane $(1 \mathrm{~g} / 40 \mathrm{ml})$ for $6 \mathrm{~h}$ in Soxhlet's apparatus.

The methanolic extract of mustard seed meal was used for the determination of antioxidant potential i.e. 2, 2diphenyl-1-picryl hydrazine scavenging activity (DPPH), total antioxidant activity (TAA) and iron chelating activity. Free radical 2, 2-diphenyl- 1-picryl hydrazine (DPPH) scavenging activity was monitored as described by Yen and Duh (1993). The percent radical scavenging capacity was calculated by the formula; $\mathrm{A}_{\mathrm{c}}-\mathrm{A}_{\mathrm{s}} / \mathrm{A}_{\mathrm{c}} * 100$ (where $\mathrm{A}_{\mathrm{c}}=$ absorbance of control and $\mathrm{A}_{\mathrm{s}}=$ absorbance of samples). The total antioxidant activity was estimated by the method of Prieto et al. (1999). The antioxidant activity was expressed relative to that of ascorbic acid. The chelating activity of $\mathrm{Fe}^{2+}$ was estimated by the method of Hsu et al. (2003). The method is based on the principle of the $\mathrm{Fe}^{2+}$ chelating ability of the antioxidant by measuring the ferrous iron -ferrozine complex formed at $562 \mathrm{~nm}$. The Chelating activity was calculated by the equation; Scavenging effect $(\%)=\left[1-\left(A_{t} / A_{0}\right)\right]^{* 100}$ (where $A_{t}$ is the absorbance of the sample and $A_{0}$ is the absorbance of the control at $562 \mathrm{~nm}$ ).

Tryptophan content was determined by the method of Spies and Chambers (1949) by addition of p-methylbenzaldehyde and $19 \mathrm{~N} \mathrm{H}_{2} \mathrm{SO}_{4}$ to defatted seed meal and then this mixture was kept in dark room for 12 hours. Finally, O.D. was taken at $454 \mathrm{~nm}$ after addition of $0.045 \% \mathrm{NaNO}_{2}$. Colorimetric method by Horn et al. (1946) was used for the estimation of methionine content. Firstly defatted sample was acid hydrolyzed with $2.5 \mathrm{~N} \mathrm{HCl}$ for 18 hours. After that dried residue was used for decolourisation by activated charcoal and volume was made up with warm distilled water. Then
$5 \mathrm{~N} \mathrm{NaOH}, 10 \%$ sodium nitroprusside, $3 \%$ glycine and orthophosphoric acid were added and shaken well and absorption was measured at $520 \mathrm{~nm}$. Protein content was determined by the standard method of Kjeldahl using a VAP-50-Gerhardt apparatus. The fatty acids were analyzed by the gas chromatography. The methyl esters of fatty acids were prepared by method of Vasudev et al. (2008).

\section{RESULTS AND DISCUSSION}

The mustard seed meal is superior to soybean and groundnut seed meal in terms of having essential amino acids, minerals and less content of phytic acid which reduces the bioavailability of minerals. The mustard oil is mainly utilized for edible purposes; however, depending upon the fatty acid composition, it can also be utilized for a number of non-food, fuel/non -fuel industrial products. The fatty acid composition of different Indian mustard varieties is presented in Table 1. It is evident that the newly developed variety $\mathrm{RH}$ 0749 synthesized high content of erucic caid (44.70\%) and low content of oleic acid (11.20\%), whereas, it had lowest content of linoleic acid (15.10\%) and highest content of linolenic acid (19.70\%) among all the genotypes studied. Oil high in oleic acid has demand in commercial food-service applications due to a long self-life and cholesterol- reducing properities (Kaushik and Agnihotri, 2000). High erucic acid content, however, is beneficial for polymer industry, whereas, low erucic acid $(<2 \%)$ is recommended for food purposes. In the present study, the genotype RH (OE) 0801 and EC 597328 synthesized the erucic acid within the permissible limits $(\leq 2.0 \%)$ and with high oleic acid content of 42.51 and $39.00 \%$, respectively. The erucic acid content in remaining two genotypes (EC 597340 and JM 6011) was recorded slightly in higher side ( 2.50 and $5.03 \%$, respectively) of the recommended content. All the genotypes (except RH 0749) synthesized medium content of essential fatty acids, i.e. linoleic acid (28.19-30.98\%) and linolenic acid (15.84$17.91 \%)$.

Table 1. Fatty acid composition of five different Indian mustard genotypes.

\begin{tabular}{lcccc}
\hline \multirow{2}{*}{ Genotypes } & \multicolumn{4}{c}{ Fatty acid (\%) } \\
\cline { 2 - 5 } & Oleic acid & Linoleic acid & Linolenic acid & Erucic acid \\
\hline RH (OE) 0801 & 42.51 & 28.45 & 15.84 & 1.51 \\
JM 6011 & 39.15 & 28.19 & 17.91 & 5.03 \\
EC 597328 & 39.00 & 29.73 & 17.50 & 2.00 \\
EC597340 & 40.53 & 30.98 & 16.47 & 2.50 \\
RH 0749 & 11.20 & 15.10 & 19.70 & 44.70 \\
\hline
\end{tabular}

Table 2. Protein content and other biochemical parameters of five different Indian mustard genotypes.

\begin{tabular}{lcccc}
\hline Genotypes & $\begin{array}{c}\text { Protein } \\
\text { content (\%) }\end{array}$ & $\begin{array}{c}\text { Glucosinolate content }(\boldsymbol{\mu} \\
\text { mole/ } \mathbf{g} \text { defatted seed meal) }\end{array}$ & $\begin{array}{c}\text { Total antioxidant activity } \\
\text { (mg/g AAE) }\end{array}$ & $\begin{array}{c}\text { Metal ion chelating } \\
\text { activity (\%) }\end{array}$ \\
\hline RH (OE) 0801 & 33.57 & 60.10 & 17.94 & 24.52 \\
JM 6011 & 36.02 & 53.60 & 19.85 & 30.25 \\
EC 597328 & 33.51 & 42.80 & 18.08 & 24.32 \\
EC 597340 & 35.43 & 79.79 & 19.44 & 23.35 \\
RH 0749 & 38.01 & 63.82 & 20.41 & 32.58 \\
\hline
\end{tabular}




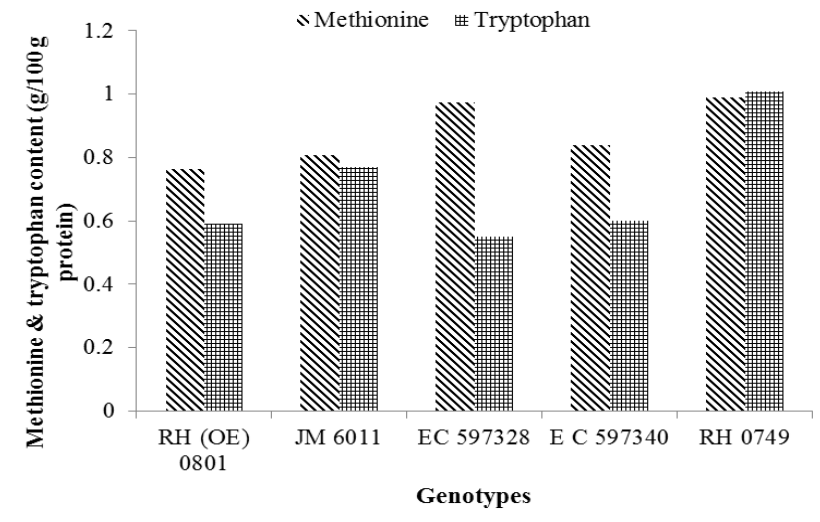

Fig. 1. Methoinine and tryptophan content of five different Indian mustard genotypes.

The data on protein content and other biochemical parameters recorded in five different genotypes is presented in Table 2 which revealed that maximum protein content $(38.01 \%)$ was recorded in important variety RH 0749 followed byJM $6011(36.02 \%)$ and EC 597340 (35.43\%). Protein content in EC 597328 was minimum $(33.51 \%)$ which was at par with RH (OE) 0801 (33.57). Chauhan and his coworkers (2010) also found high amount of protein in Indian mustard. Besides having a good amount of protein, the seed meal is also rich in essential amino acids which increase its suitability for feed. The maximum tryptophan content was observed in RH 0749 (1.01 g/100g protein) followed by JM 6011 (0.77 g/100g protein), EC 597340 (0.60 g/100g protein), RH (OE) 0801 (0.59 g/100g protein) and EC 597328 (0.55 g/100g protein) (Fig. 1.) The methionine content ranged from 0.764 (RH (OE) 0801 ) to $0.990 \mathrm{~g} / 100 \mathrm{~g}$ protein (RH 0749) among all the tested genotypes (Fig. 1.) Verma and Baigh (2012) also observed methionine and tryptophan content, 1.129 and $0.850 \mathrm{~g} / 16 \mathrm{~g} \mathrm{~N}_{2}$, respectively in Indian mustard.

The antioxidant properties of seed meal also contribute in its increased uses in food industries and health management. To check the antioxidant potential all the five genotypes were analyzed for DPPH activity, total antioxidant activity and metal ion chelating activity. For determining the DPPH activity, $\mathrm{IC}_{50}$ value was determined in methanolic extract of seed meal. All the genotypes showed about $50 \%$ inhibition in the concentration of $3.0 \mathrm{mg}$ dry seed meal (Fig. 2). These results are in accordance with those of Kumari et al. (2016), while Dua et al. (2014) who reported $\mathrm{IC}_{50}$ value 2-25 $\mathrm{mg}$ of seed meal. Saxena and his coworkers (2011) also found that the methanolic extract of fenugreek was better for determining free radical scavenging activity than any other solvent. The highest antioxidant activity was recorded in RH $0749(20.41 \mathrm{mg} / \mathrm{g})$ followed by JM 6011 (19.85 mg/g), EC 597340 (19.44 $\mathrm{mg} / \mathrm{g})$, EC 597328 (18.08 mg/g) and RH (OE) 0801 (17.94 mg/g) (Table 2). Similarly, high antioxidant activity in Indian mustard was also reported by Bala et

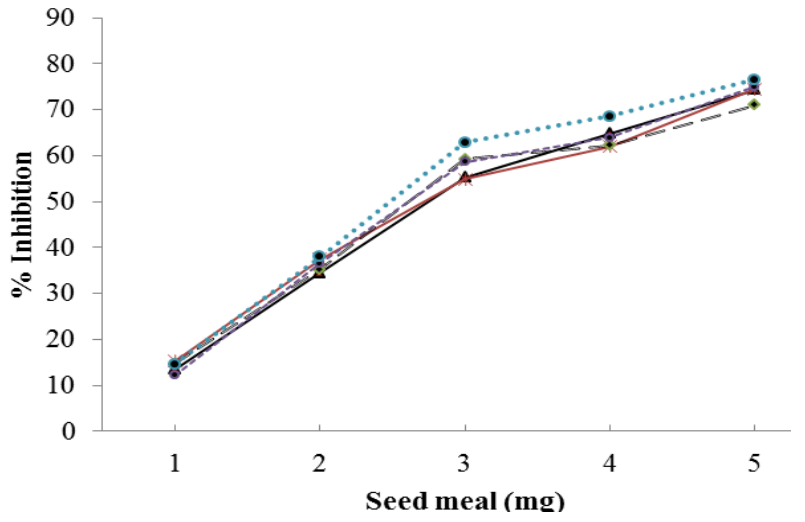

Fig. 2. DPPH inhibition (\%) in five different Indian mustard genotypes.

al., (2011) and Kumari et al., (2016). Natural plant based antioxidants are far better than the artificial one because of their less allergenic properties and ethical acceptance. Transition-metals like iron, nickel and copper are well known for their functions as biocatalyst and pro-oxidant functions, which promote the undesirable oxidation. The metal chelating activity in all the genotypes varied from 23.35 (EC 597340) to 32.58 (RH 0749) \% (Table 2). Similar results were also reported earlier by Ishtiaque et al. (2013) in Indian mustard.

Apart being nutritional better, the major drawback of seed meal of Indian mustard is glucosinolates, which are well known for their antithyriod effect and reduction in feed palatability and iron absorption (Bille et al, 1983). The glucosinolate content ranged from $63.82-$ $79.79 \mu \mathrm{mole} / \mathrm{g}$ defatted seed meal. The highest glucosinolate content was recorded in the genotype EC 597340 (79.79 $\mu$ mole/g defatted seed meal) followed by RH 0749 (63.82 $\mu$ mole/g defatted seed meal), RH (OE) 0801 (60.10 $\mu$ mole/g defatted seed meal), JM 6011 (53.60 $\mu$ mole/g defatted seed meal) while minimum glucosinolate content was observed in JM 6011 (42.80 $\mu \mathrm{mole} / \mathrm{g}$ defatted seed meal) (Table 2). Thus, the present study revealed that Indian mustard genotypes investigated had, in general, low level of saturated fatty acids $(<7 \%)$. The methanolic extract of seed meal had different levels of antioxidant activity, metal ion chelating activity and scavenging effect on free radicals. Among the tested genotypes, RH 0749 performed better in terms of protein content, antioxidant activity and limiting amino acids. Present study therefore, might be helpful in breeding of Indian mustard germplasm having desirable characterstics with enhanced health promoting and nutritive qualities.

\section{Conclusion}

The seed meal of Indian mustard genotypes was observed to be qualitatively better in terms of limiting amino acids (methionine $(0.764$ to $0.990 \mathrm{~g} / 100 \mathrm{~g}$ protein) and tryptophan (0.55 to $1.01 \mathrm{~g} / 100 \mathrm{~g}$ protein) and antioxidants (The total antioxidant activity ranged 
from $17.94 \mathrm{mg} / \mathrm{g}$ to $20.41 \mathrm{mg} / \mathrm{g}$, The metal chelating activity varied from 23.35 to $32.58 \%$ etc.). This can be used as a source of natural antioxidant in food industries and animal feed as well. The variety $\mathrm{RH} 0749$ was observed as a potent variety due to higher total antioxidant activity, metal ion chelating activity, protein content, methionine and tryptophan content.

\section{REFERENCES}

Andlauer, W. and Furst, P. (1998). Antioxidative power of phytochemicals with special reference to cereales. Cereal Foods World, 43: 356-359

Bala, M. and Singh, M. (2012). Non-destructive estimation of total phenol and crude fiber content in intact seeds of rapeseed-mustard using FTNIR. Industrial Crops and Products, 42: 357-362

Bala, M., Kumar, S. and Singh, L. (2011). Antioxidant potential of rapeseed mustard seed meal extracts. Indian journal of Agricultural Biochemistry, 24: 154-174

Bell, J. M. (1984). Nutrients and toxicants in rapeseed meal: a review. Journal of Animal Science, 58: 996-1010

Bille, N., Eggum, B. O., Jacobsen, I., Olsen, O. And Sørensen, H. (1983). The effects of processing on antinutritional rape constituents and the nutritive value of double low rapeseed meal, Zeitschr. Tierphysiol Tierernährungu.Futtermittelkd, 49: 148-163

Chauhan, J. S., Kumar, S., Singh, K. H., Meena, S. S. and Meena, M. L. (2010). Oil and Seed Meal Quality Indices of Indian Rapeseed-Mustard Varieties. Journal of Plant Biochemistry \& Biotechnology, 19(1): 83-86

Dua, A., Chander, S., Aggrawal, S. and Mahajan, R. (2014). Antioxidants from defatted Indian mustard (Brassica juncea) protect biomolecules against in vitro oxidation. Physiology and Molecular Biology of Plants, 20:539543

Halliwell, B. (2010). Free radicals and antioxidants-quo vadis? Trends in Pharmacological Sciences, 32:125130

Horn, M. J., Jones, D. B. and Blum, A. E. (1946). Colorimetric determination of methionine in proteins and foods. Journal of Biological Chemistry, 116:313320

Hsu, C. L., Chen, W., Weng, Y. M. and Tseng, C. Y. (2003). Chemical composition, physical properties, and antioxidant activities of yam flours as affected by different drying methods. Food Chemistry, 83: $85-92$

Ishtiaque, S. Khan, N., Siddiqui, M. A, Siddiqi, R. and Naz,
S. (2013). Antioxidant potential of the extracts, fractions and oils derived from oilseeds. Antioxidants, 2: 246-256

Kaushik, N. And Agnihotri A. (2000). GLC analysis of Indian rapeseed-mustard to study the variability of fatty acid composition. Biochemical Society Transactions, 28 (6): $581-583$

Kumari, N., Avtar, R., Sharma, B. and Thakral, N. (2016) Antioxidant potential of seed meal of different Indian mustard genotypes. Journal of Oilseeds Brassica, 7(1): 63-67

Prieto, P., Pineda, M. and Aguilar, M. (1999). Spectrophotometric Quantitation of Antioxidant Capacity through the Formation of a Phosphomolybdenum Complex: Specific Application to the Determination of Vitamin E1. Analytical Biochemistry, 269: 337-341

Priyamedha, S., Singh, B. K., Ram, B., Kumar, A., Singh, V. V., Meena, M. L. and Singh, D. (2014). Development and evaluation of double low quality lines in indian mustard (Brassica juncea L. Czern \& Coss). SABRAO Journal of Breeding and Genetics, 46 (2): 274-283

Saxena, S. N., Karwa, S., Saxena, R., Sharma, T., Sharma, Y. K., Kakani, R. K. and Anwer, M. M (2011). Analysis of antioxidant phenolics and flavonoid content of fenugreek seed extract. International Journal of seed Spices, 1: 38-43

Singh, B. K., Bala, M. and Rai, P. K. (2014). Fatty acid composition and seed meal characteristics of Brassica and allied genera. National Academy Science Letter, 37: 219-226

Spies, J. R. and Chambers, D. C. (1949). Chemical determination of tryptophan in protein. Analytical Chemistry, 21: 1249-1265

Sutariya, D. A., Patel, K. M., Bhadauria, H. S, Vaghela, P. O., Prajapati, D. B., Parmar, S. K. (2011). Genetic diversity for quality traits in Indian mustard (Brassica juncea L.). Journal of Oilseed Brassica, 2(1): 44-47

Vasudev, S., Yadava, D. K., Malik, D., Tanwar, R. S. and. Prabhu, K. V. (2008). A simplified method for preparation of fatty acid methyl esters of Brassica oil. Indian Journal of Genetics and Plant Breeding, 68(4): 456-458

Verma, K. C. and Baigh, M. A. (2012). Response of phosphorous and molybdenum on yield and quality attributing characters of Indian mustard (Brassica juncea L. Czern \& Coss). The Bioscan, 7(3): 437-440

Yen, G. C. and Duh, P. D. (1993). Antioxidative properties of methanolic extract from peanut hulls. Journal of American Oil Chemists Society, 4: 383-386 